\title{
Matematik Öğretmenlerinin Üstün Zekâlılar Hakkındaki Görüşlerinin incelenmesi: Bir Metafor Çalışması
}

\section{Investigating Mathematics Teacher Perceptions' of Gifted Students Using Metaphors}

\section{Mehmet KIRMIZI*}

\section{Kamuran TARIM ${ }^{* *}$}

Öz. Metaforlar ile bir zihinsel şema başka bir zihinsel şema altında açıklanmasına olanak sağlayan güçlü zihinsel yapılardır. Metaforlar yardımı ile bir kişinin herhangi bir konu hakkındaki görüş ve düşünceleri anlaşılabilir. Bu çalışmada, matematik öğretmenlerinin meslek hayatları boyunca ( $n=115)$, üstün zekâlılar hakkında edindikleri tecrübeler, üstün zekalılar denilince zihinlerinde beliren imgeler ve üstün zekâlılar hakkındaki görüşleri metaforlar yardımı ile incelenmiştir. Oluşturulan bu metaforlar 10 tema altında toplanmıştır ve bu temalar: Hassas Bir Eğitim", "Farklı,, "Parlak Öğrenci" " "Yüksek Zihinsel Kapasite", "Değerli", "Anlaşılmayan Birey", "Faydalı", "Gelişen", "Zararlı Olabilir" ve "Enderlik" şeklindedir. Araştırmanın sonucunda çalışmaya katılan öğretmenlerin üstün zekâlıların onların eğitsel intiyaçlarının farkında olduğu söylenebilir. Buna karşın çalışma grubu içerisindeki küçük bir grubun üstün zekâlıları, üstün zekâlı olmayan fakat başarııı olan "parlak" öğrencilerle karşılaşsırdıkları söylenebilir.

Anahtar Kelimeler: Üstün zekalılar, matematik öğretmenleri, metafor.

Abstract. Metaphors are powerful mental constructs that shape human thinking and behavior. In this respect, it is possible to know someone's belief and thought through his or her use of metaphor for any phenomena. In addition three is scientific pieces of evidences that math teachers are seen as an intelligent person in the eye of their students. In this study, mental images and perceptions of these inteligent people, math teachers $(n=115)$, about gifted students have been investigated by using metaphors. All metaphors are gathered around 10 themes and these themes are as follows: "a sensitive education", "different", "bright student", "high intellectual capacity", "precious", "developing", "enigma", "beneficial", "rare" and "can be a cthe urse". As a result of this study, it can be said the majority of participants are aware of gifted students and their educational needs. On the contrary, a minority of the participants mixed gifted ones with high-achiever but not gifted "bright students".

Keywords: Gifted, math teachers, metaphors.

\section{Toplumsal Mesaj.}

Matematik öğretmenlerinin üstün zekâlılar hakkındaki görüşlerinin incelendiği bu çalışmada, öğretmenlerin büyük bir kısmının üstün zekâlıların ve onların eğitsel intiyaçlarının farkında olduğu sonucuna varılmıştır. Buna karşın katılımcıların küçük bir kısmının ise üstün zekâlıları başarılı fakat üstün olmayanlar öğrenciler ile karıştırdığı söylenebilir.

Public Interest Statement.

In this study the perceptions of math teachers have been investigated. Results of this study have revealed that majority of the participants were awere of gifted students and their educational needs. On the contrary a minority of the participant have confusion about gifted students and non-gifted bright students.

\footnotetext{
* Orcid ID: http://orcid.org/0000-0002-1925-1016, Hasan Sünnüoğlu Ortaokulu, mhkirmizi@gmail.com

** Orcid ID: http://orcid.org/0000-0002-2048-5207, Prof. Dr., Çukurova Üniversitesi, ilköğretim Matematik Öğretmenliği, kamuran.tarim@gmail.com
} 


\section{GíRiş}

Metafor kavramı en basit anlamı ile TDK'ya göre edebiyat, mecaz, istiare vb anlamlarına gelmektedir. Buna karşın bilimsel literatürde Yıldırım ve Şimsek (2013: 238) insanların metaforlar (mecazlar) yardımıyla doğayı ve çevresini daha iyi algıladıklarını ve metaforların olguları bir alandan diğer bir alana taşıdıklarını ve gerçekleri süzerek basit bir şekilde ifade ettiklerini belirtmişlerdir. Metaforlar iki benzeşmez şeyin arasında ilişki kurulabilmesine olanak sağlaması ve bir zihinsel şemanın başka zihinsel şema üzerinden açıklanmasına olanak sağlar. Benzetmeler, teşbihler, mecazlar dili süslemek gibi sanatsal bir işlev görürken metaforlar ise zihinsel imgelerin, düşüncelerin ve kavramların simgelenmesi için kullanılır (Saban, 2008). Shuelle'nin belirttiği gibi "Eğer bir resim 1000 kelimeye bedelse, bir metafor da 1000 resme bedeldir. Çünkü, bir resim statik bir imge sunarken, bir metafor bir olgu hakkında düşünmek için zihinsel bir çerçeve sunmaktadır" (akt: Saban, 2008).

Metaforlar hayatımızın her alanındadır. Metaforlar yardımı ile her alandaki düşünceler, anlamlar, açıklamalar vb. anlamlı hale gelirler ve farklı entelektüel ve bilişsel düzeydeki insanların birbirlerini anlamalarına yardımcı olurlar (Yıldırım ve Şimsek, 2013: 237). Metaforlar özellikle yeni fenomenleri, tanımlamak ve anlamak için kullanılırlar çünkü onlar birinin iyi anladığı bir durumu anlamayan birine taşıma görevini üstlenirler (Schultze ve Orlikowski, 2001). Metaforları kullanmak konuşmacıya ve dinleyiciye gerçeği sıradanlıktan ve sıkıcılıktan göze çarpana dönüştürme gücü verir. Metaforlar geçmiş zamanların sihirli sözcükleri gibidir. Sözcükleri kullanmak konuşmacıya insanların en iyi ve tanınmayanı anlayacağı ve inanacağı yeni mekanizmalar yapma ve dünyayı yeni bir bakış açısı ile görme yeteneği verir (Kendal ve Kendal, 1993). Nitel araştırma denilince akla gelen ilk isimlerden biri olan Patton ise metaforların bulguları iletmenin güçlü ve zeki yolu olabileceğini belirtmiş ve bunun yanında hem okuyucu için hem de analiz yapan kişi için eğlenceli olabileceğini belirtmiştir (Patton, 2014: 505).

Metaforlar sosyal bilimlerin çeşitli alanlarında 1980'lerden beri kullanılmaktadır (Yıldırım ve Şimşek,2013). Buna paralel olarak uluslararası ve ulusal literatürde pek çok metafor araştırmaları mevcuttur (Oxford vd; 1998, Nikitina ve Furuoka, 2008; Çırak, 2014; Cerit, 2008; Kunt ve Tortop, 2013; Çapan, 2010; Özsoy, 2014; Tolan, 1997; Olthouse, 2014). Oxford vd (1998) katılımcılardan geçmiş öğrenme yaşantıları sırasında sıkıntı yaşadıkları, özellikle sevmedikleri veya özellikle sevdikleri öğretmenleri tarif etmelerini istemiş, bu anlatılar sırasında araştırmacılar, çalışma grubundakilerden metafor kullanmaları yönünde bir telkinde bulunmamış buna karşın katılımcıların hepsi metaforlar yardımı ile durumu açıkladıklarını belirtmişlerdir. Yine bu çalışmada Oxford vd. oluşturulan metaforlar yardımıyla "öğretmen" (özel olarak dil öğretmeni) kavramı ile ilişkin dört felsefik (sosyal düzen, kültür aktarıcı, öğrenci merkezli ve sosyal devrim/değişim) bakış açısı ile uyum gösterdiğini tespit etmişlerdir. Nikitina ve Furuoka (2008) ise 23 üniversite öğrencisine, dil öğretmeni kavramı hakkında metaforlar oluşturtmuş ve bu metaforların yardımı ile Asya eğitim içeriğinin Oxford vd. (1998) sıraladığı öğretmen kavram ilgili dört önemli felsefi görüşle uygunluk gösterdiğini tespit etmişlerdir.

Çırak (2014), çalışmasında, 83 öğretmene "Öğrenci ...e benzer çünkü..............." ifadesini tamamlatarak, öğretmenlerden 'öğrenci' kavramına ilişkin metaforlar oluşturmalarını isteyerek oluşturulan metaforları 8 farklı kategori altında toplamış. Bu kategoriler: Bilgi alıcısı, üretilen ve şekillendirilen, yansıtıcı, çaba gösteren, sınırlandırılan, değerli, amaçsız ve yol gösterilecek şeklindedir. Oluşturulan metaforların öğretmenlerin çalıştıkları okulların sosyo ekonomik düzeyine göre farklılaştığını tespit etmiştir. Cerit (2008) öğrencilerin $(n=600)$, öğretmenlerin $(n=203)$ ve yöneticilerin ( $n=51)$ öğretmen kavramı hakkında oluşturulmuş metaforları tercih edilme düzeylerini belirlemiş. Çalışmasının sonuçlarına göre öğretmenlik ile en çok tercih edilen metaforların bilgi kaynağı ve dağıtıcısı, anne-baba, arkadaş, rehber ve çevresini aydınlatan kişi olduğunu tespit etmiştir. Buna karşın otoriter, bahçıvan, yıkıcı kişi, zarar verici vb metaforların ise tercih edilmediğini ve öğretmenler ile yöneticiler arasında bir farklılık olmadığını bunun yanında öğretmen ile öğrenciler arasında anlamlı farklılık olduğunu tespit etmiştir. 
Üstün zekalılar ve eğitimleri hakkında da literatürde metaforik çalışmalar vardır ama bu çalışmalar genellikle üstün zekalı öğrenciler (Kunt ve Tortop, 2013; Özsoy, 2014), aileri (Özsoy, 2014; Ateş, 2018) ve bazen de öğretmen ve öğretmen adayları (Çapan, 2010, Olthose, 2014) ile yapılmıştır. Bu çalışmaların bazılarını detaylı bir şekilde incelendiğinde Kunt ve Tortop'un (2013) çalışmalarıda üstün zekâlıların ( $n=87)$ Bilim Sanat Merkezleri hakkındaki görüşlerinin bu kurumların kuruluş amaçları ile benzerlikler gösterdiğini metaforlar yardımı tespit ettikleri anlaşılır. Benzer bir diğer çalışmada ise Özsoy (2014) Bilsem'e devam eden öğrencilerden, çalışan öğretmenlerden ve buradaki öğrencilerin velilerinden "üstün yetenekli öğrenci" kavramını nasıl algıladıklarını tespit etmek için onlardan üstün zekalılar hakkında metaforlar oluşturmalarını istemiştir. Bu oluşturulan metaforları da "yüksek performans gösteren", "uygun eğitime gereksinim duyan", "gizemli", "değerli", "yaşıtlarından farkı", "geniş kapasiteli" ve "çok yönlü" kategorileri altında toplamıştır. Metaforlar yardımı ile bu üç grubun üstün zekâlılar hakkındaki görüşlerinin benzerlikler/ paralellikler gösterdiğini tespit etmiştir. Bir diğer çalışma da ise Çapan (2010) 211 öğretmen adayından üstün zekalılar hakkında metaforlar oluşturmalarını isteyerek onların üstün zekalıları ve eğitimleri hakkındaki görüşlerini incelemiştir. Çalışmanın sonuçlarında katıımcıların oluşturdukları metaforları 13 başlık altında toplamıştır. Bu başlıklardan bazıları yüksek performans gösteren, yetersiz koşullarda gelişmeye çalışan, uygun eğitime gereksinim duyan, gizemli ve anlamak için çaba gerektiren şeklindedir. Araştırmasının sonuçları arasında Çapan öğretmen adaylarının bu çocukların gelişimlerinin sorumluluğunu kabul eden bir düşünce içerisinde olduklarını belirtmiştir.

Bu alanda yurtdışında yapılmış önemli çalışmalardan bir tanesi olan Olthouse (2014), 124 öğretmen adayından konu ile ilgili metaforlar oluşturmalarını istediği çalışmasında katılımcıların oluşturduğu metaforları gruplandırdıktan sonra oluşan grupların Dai (2009) yılında belirttiği üstün zekalılar eğitiminde yaşanan tartışmalar ile büyük bir benzerlik gösterdiğini tespit etmiştir. Oluşturduğu grupların 5 tanesinin Dai' nin gerginlikleri ile birebir örtüştüğünü 1 tanesinin ise örtüşmediğini belirtmiştir. Yukarıda bahsedilen çalışmalar üstün zekalı bireyler, üstün zekalı bireye sahip aileler, öğretmen ve bazen de öğretmen adayları ile yapılmıştır. Buna karşın matematik tarih boyunca zeka ile ilişkilendirilen bir disiplin olagelmiştir. Ayrıca matematiksel-mantıksal zeka, çoklu zeka kuramında zihnin temel bileşenlerinden bir tanesi olarak kabul edilmektedir (Gardner, 1987). Ek olarak literatürde matematik dersinin öğrenciler tarafından "zeka gerektiren bir ders" ve "zor ve sıkıcı bir ders" diye nitelendirildiği ve yine öğrencilerin matematik öğretmenlerini "zeki bir insan" şeklinde tanımlandığını belirten çalışmalar vardır (Ada, 2013). Matematiğin ve matematik öğretmeninin zeka ile bu kadar ilişkilendirilmesine rağmen literatürde matematik öğretmenlerinin meslek hayatlarında üstün zekalılar hakkında edindikleri tecrübenin incelendiği herhangi bir çalışmaya rastlanmamıştır. Diğer bir deyişle matematik öğretmenlerinin üstün zekalılar hakkında sahip oldukları zihinsel imgelerin incelenmesine ihtiyaç vardır.

$\mathrm{Bu}$ araştırmada ise matematik öğretmenlerinin üstün zekalılar hakkındaki görüşleri metaforlar yardımı ile incelenecektir. Böylelikle literatürdeki boşluğun dolddurulması amaçlanmaktadır. Bu amaç kapsamında aşağıdaki sorunun cevabı aranacaktır:

"Matematik öğretmenlerinin üstün zekalılar hakkında oluşturdukları metaforlar nelerdir ve bu metaforlar hangi kategoriler altında toplanabilir?"

\section{YÖNTEM}

\subsection{Araştırma Modeli}

Bu çalışmanın amacı matematik öğretmenlerinin üstün zekâlılar hakkındaki görüşlerinin incelenmesi olduğundan bu çalışmada da nitel araştırma yöntemlerinden "olgu bilim" kullanılmıştır. Yıldırım ve Şimşek (2013)'e göre olgu bilim farkında olunan fakat tam anlamı ile farkında olamadığımız olgulardır. Merriam (2013)' göre ise olgu bilimin temelinde deneyimin var olduğunu ve bu deneyimin nasıl bilince dönüştüğü vardır. Patton olgu bilimin günlük deneyimlerin anlamı veya doğası hakkında derinlemesine bir anlayışın kazanılmasını amaçladığını ve bu amaç 
doğrultusunda olgu biliminin temel sorusunun "Bir insan grubu veya kişinin bu fenomene ilişkin yaşanmış deneyiminin anlamı, yapısı ve özü nedir" olduğunu belirtmektedir (2014 s:104).

\section{2 Çalışma Grubu}

Bu araştırmanın çalışma grubunu 2015 - 2016 eğitim öğretim yılında Şanlıurfa'nın Ceylanpınar ilçesi ile Kilis ilinin merkez okullarında görev yapan toplam 115 matematik öğretmeni oluşturmaktadır. Katılımcıların çalışmaya seçilmesi için örneklem seçim yöntemlerinden basit seçkisiz örnekleme yöntemi kullanılmıştır. Basit seçkisiz örnekleme yönteminde tüm birimlerin örneğe seçilmeleri eşit şansa sahiptirler (Büyüköztürk vd, 2014). II ve ilçe milli eğitim müdürlüklerinden gerekli izinler alınarak yapılan bu çalışmada katılımcılar veri toplama aracını "gönüllü" olarak doldurmuşlardır. Çalışmaya katılan öğretmenlerden metaforları geçerli kabul edilenlere $(n=94)$ ait cinsiyet, tecrübe, eğitim vb. değişkenlere ait betimsel istatistikler Tablo 1'deki gibidir.

Tablo 1. Çalışma grubunun çeşitli değişkenlerine göre dağılımı

\begin{tabular}{lcc}
\hline Değişken & Frekans (f) & Yüzde(\%) \\
\hline Cinsiyet & 55 & 58,5 \\
Kadın & 39 & 41,5 \\
Erkek & & \\
Okul türü & 50 & 53,2 \\
Ortaokul & 44 & 46,8 \\
Lise & &
\end{tabular}

(Tablo 1'in devamı)

\begin{tabular}{lcc}
\hline Tecrübe & 63 & 67,0 \\
$0-5$ yıl & 17 & 18,1 \\
$5-10$ yıl & 5 & 5,3 \\
$10-15$ yıl & 4 & 4,3 \\
$15-20$ yıl & 5 & 5,3 \\
$20-25$ yıl & - & - \\
25 ve daha fazla & & 94,7 \\
Eğitim & 89 & 5,3 \\
Lisans & 5 & - \\
Yüksek Lisans & - & \\
Doktora & &
\end{tabular}

Yukarıdaki tabloya göre çalışmaya katılan öğretmenlerin $\% 58,5^{\prime} i(n=55)$ bayan ve $\% 41,5^{\prime} i$ ise $(n=44)$ erkektir. Katılımcıların $\% 53,12^{\prime} l i k$ kısmı $(n=50)$ ortaokul, ilköğretim matematik, öğretmeni buna karşılık ise $\% 46,8^{\prime}$ lik kısmı $(n=44)$ lise matematik öğretmenidir. Çalışma grubundaki öğretmenlerin $\% 68,3^{\prime} \mid$ ük ( $n=69$ ) meslekteki ilk 5 yılın içerisinde olduğu belirlenmiştir.

\subsection{Veri Toplama Aracı ve Verilerin toplanması}

Bu çalışmada araştırmacılar tarafından hazırlanan veri toplama aracı kullanılımışır. Veri toplama aracının ilk kısmında katılımcıların kişisel bilgilerinin yer aldığı (tecrübe, cinsiyet, okul türü vb) bölüm, ikinci kısmında ise katılımcılardan "üstün zekalılar .gibidir, çünkü....

cümlesini tamamlayarak üstün zekalılar hakkında birer metafor oluşturmaları istenmiş daha sonra 
da neden bu metaforu oluşturduklarını açıklamaları istenmiştir. Yıldıım ve Şimşek (2014) aynı metaforun farklı bireyler için farklı anlamlar taşıyabileceğini ve bundan dolayı bir metaforun hangi amaçla kullanıldığını ancak "neden", "niçin" vb. sorularla tespit edilebileceğini belirtmişlerdir.

Veri toplama sürecinde araştırmacı 2015-2016 eğitim öğretim yılının haziran ayının ilk haftası Şanlıurfa'nın Ceylanpınar ilçesinin merkez okullarında görev yapan daha sonra ise yine aynı dönemde Kilis ilinin merkezinde görev yapan matematik öğretmenlerinden metaforlar oluşturulması istenmiştir.

\subsection{Verilerin Analizi}

Bu çalışmada verilerin analiz edilmesi için "içerik analizi" yöntemi kullanılmıştır. İ̧̧erik analizinde veriler derin bir şekilde incelenerek betimsel yaklaşımlarla fark edilmeyen konuları ve noktaları açığa çıkarır (Yıldırım ve Şimşek, 2013). Verilen analizi yapılabilmesi için öncelikle katılımcıların oluşturdukları metaforların ayıklanması gerekmektedir. Bu aşamada öğretmenler tarafından oluşturulan metaforlar incelenerek metafor kavramına uymayanlar elenmiştir. Üç öğretmenin üstün zekalı öğrenci için metafor kavramı sunmak yerine "düşünme becerisine sahip", "aşırı yaratıııdır" ve "fazla itiraz ederler" şeklinde onların var olan özelliklerinden bahsettikleri için elenmiştir. Başka bir öğretmen ise "gözlük" metaforunu sunmuş ve "Gözlüklü öğrencilerde çokbilmiş bir hava var. Her cevap verdiklerinde elleri gözlüklerinde oluyor." şeklinde açıklamıştır. Diğer bir öğretmen ise "bilgisayar" metaforunu oluşturmuş ve açıklamasında ise "Önüne koyduğunuz bir lego oyuncak ile size birbirinden farklı legolarla yapılacak bütün sonuçlarda araba, ev tak çıkar birden fazla öğeyi bir araya getirip sunabilir." ifadelerin kullanmıştır. Bu iki öğretmenin ise oluşturdukları metaforlar ile açıklamaları örtüşmediği için elenmiştir. Bu vb. sebeplerden dolayı toplam 21 öğretmenin metaforu ayıklanmıştır.

Veriler ayıklandıktan sonra geçerli kabul edilen toplam 94 metafor önce birinci yazar tarafından birbirleri ile benzer olanları toplam 10 alt kategoriye ayrılmıştır. Daha sonra oluşturulan bu kategoriler ve metaforlar ikinci yazar tarafından kontrol edilerek çalışmanın iç tutarlılı̆̆ı sağlanmıştır.

Araştırmaya katılan öğretmenlerin görüşlerinin aktarılmasında öğretmenlere 1'den 94' e kadar sayılar verilmiş ve sayıların yanlarına cinsiyetlerini gösteren harfler yazılmıştır [19E (Görüşünden alıntı yapılan on dokuzuncu öğretmenin erkek olduğunu; 55K (Görüşünden alıntı yapılan elli beşinci öğretmenin kadın olduğunu göstermektedir].

\section{BULGULAR}

Bu çalışmaya katılan öğretmenler tarafından oluşturulmuş 94 metaforun listesi Tablo 2'deki gibidir.

Tablo 2. Matematik öğretmenlerin oluşturdukları metaforlar ve frekansları

\begin{tabular}{lclc}
\hline Metafor & Frekans (f) & Metafor & Frekans(f) \\
\hline Bilgisayar & 10 & Akıllı telefon & 1 \\
Hesap makinesi & 3 & Altın & 1 \\
Teknoloji & 2 & Ampul & 1 \\
Su & 2 & Anlaşılmayan bir kitap & 1 \\
Sihirbaz & 2 & Ansiklopedi & 1 \\
Kapalı kutu & 2 & Balık & 1 \\
Işık & 2 & Baraj & 1 \\
Çiçek & 2 & Bitki & 1 \\
Güneş & 2 & Oksijen & 1 \\
Yağmur & 1 & Oyun halkası & 1 \\
\hline
\end{tabular}




\begin{tabular}{|c|c|c|c|}
\hline Yıldızlar & 1 & Oyun hamuru & 1 \\
\hline Taze fidan & 1 & Özgür birer kuş & 1 \\
\hline Tohum & 1 & Labirent & 1 \\
\hline Uyuyan volkanik dağ & 1 & Meyve veren ağaç & 1 \\
\hline Uzay & 1 & Mor lahana & 1 \\
\hline Soyut resimler & 1 & Mutluluk & 1 \\
\hline Susuz toprağa & 1 & Kitap & 1 \\
\hline Sünger & 1 & Kurma kollu saat & 1 \\
\hline Tahmin edilebilir değillerdir & 1 & Kuşlar & 1 \\
\hline Piyango & 1 & Kütüphane & 1 \\
\hline Sevilmeyen bir kedi & 1 & Denize & 1 \\
\hline Kalem & 1 & Depolama aygıtları & 1 \\
\hline Karınca & 1 & Kartal & 1 \\
\hline Demir & 1 & Değerli bir taş & 1 \\
\hline Kaydedici cihaz & 1 & Değirmen & 1 \\
\hline Iç içe geçmiş kutular & 1 & Deniz & 1 \\
\hline Ingiliz anahtarı & 1 & Çam & 1 \\
\hline Işlenmeye hazır maden & 1 & Çılgın & 1 \\
\hline Gizli kalmış maden & 1 & Çiçek & 1 \\
\hline Hazine & 1 & Çiçek & 1 \\
\hline Hediye kutusu & 1 & Bir toprak & 1 \\
\hline Hiperaktif öğrenci & 1 & Uzaylı & 1 \\
\hline Fonksiyon & 1 & Bozuk bir guguk saati & 1 \\
\hline Fotograf makinesi & 1 & Barajda biriken su gibidir & 1 \\
\hline Gelişmiş teknoloji & 1 & El işi & 1 \\
\hline Gezegenler & 1 & Eşsiz pırlantalar & 1 \\
\hline Elmas & 1 & Evren & 1 \\
\hline \multicolumn{3}{|c|}{ Dikkatle keşfedilmesi gereken bir dünya } & 1 \\
\hline \multicolumn{3}{|c|}{ Içinde mücevher bulunduran çok sıkı bir kutu } & 1 \\
\hline
\end{tabular}

Yukarıdaki tablodan anlaşılabileceği gibi katılımcı öğretmenler tarafından üstün zekâlılar hakkında en çok "bilgisayar" metaforu ( $\mathrm{f}=10)$ oluşturulmuştur. Bilgisayar metaforunu, "hesap makinesi", "Işık", "kapalı Kutu", "çiçek" ve "güneş" izlemektedir. Oluşturulan bu metaforlar toplam 10 tema altında toplanmıştır ve bu temalar sırasıyla "Hassas Bir Eğitim”, "Farklı", "Parlak Öğrenci” , "Yüksek Zihinsel Kapasite", “Değerli”, "Anlaşılmayan Birey", "Faydalı", "Gelişen”, "Zararlı Olabilir" ve "Enderlik” şeklindedir.

\subsection{Tema: Hassas Bir Eğitim}

Çalışmaya katılan öğretmenlerin oluşturdukları metaforların 15 tanesi bu tema altında toplanmıştır. Bu tema altında oluşturulan metaforlar ise Tablo 3'deki gibidir. 
Tablo 3. Hassas bir eğitim teması altında toplanan metaforlar

\begin{tabular}{lll}
\hline Değerli bir taş (8K) & Bitki (50K) & Bir toprak (65E) \\
Gizli kalmış maden (13K) & Oyun hamuru (52K) & Uyuyan volkanik dağ (68E) \\
Eşsiz pırlantalar (21K) & İşlenmeye hazır maden (52E) & Su (45E) \\
Taze fidan (42K) & Işık (54E) & Demir (71K) \\
Balık (43K) & El işi (55K) & Tohum (47E)
\end{tabular}

Bu tema altında toplanan metaforların ortak özelliği üstün zekâlıların eğitimleri ve bu eğitimin hassasiyetidir. Örneğin "değerli bir taş" metaforunu oluşturan öğretmen açıklama kısmında ise "Usta bir elde işlenildiğinde daha da değerli ve anlamlı bir hal alır. Işıldar ve değeri artar." (9K) Benzer şekilde "El işi" metaforunu oluşturan öğretmen ise "Hassasiyet gerektirir. Yanlış bir ilmek, yanlış bir yönlendirme ortaya sadece zaman kaybından başka bir ürün vermez ancak doğru ve hassas bir işçilikle ortaya bir şaheser çıkabilir." (55K) şeklinde oluşturduğu metaforu açıklamıştır. "taze fidan" metaforunu oluşturan öğretmen ise "Sulandıkça serpilir, gelişir, dal budak salar. Hem kendine hem etrafına yardımcı olur. Kendi geliştikçe altında (gölgede) oturanlar artar." (42K) şeklinde ifade etmiştir.

\subsection{Tema: Farklı}

Bu tema altında toplanan metaforların ortak özelliği üstün zekâlı öğrencilerin "farklı" veya "beklenmedik" olmalarıdır. Bu tema altında toplana metaforlar Tablo-4'deki gibidir.

Tablo 4. Farklı teması altında toplanan metaforlar

\begin{tabular}{lll}
\hline Cin (18E) & Çılgın (33E) & Soyut Resimler (11E) \\
Mor lahana (58K) & Güneş (34E) & İngiliz Anahtarı (12K) \\
Deniz (37E) & Yıldızlar (54E) & Fonksiyon (22K) \\
Sihirbaz (59E) & İç içe geçmiş kutular (60K) & Kitap (67E) \\
Uzay (72E) & Bilgisayar (76E) &
\end{tabular}

Bu tema altındaki "cin" metaforunu oluşturan öğretmen oluşturduğu metaforu şöyle açıklamıştır: "Beklenmedik sorular sorar ve sorduğumuz sorulara beklenmedik cevaplar verirler. Olaylara herkesin bakmadığı farklı bakış açıları getirirler." (18E). Bu temadaki diğer bir metafor olan "sihirbaz" metaforudur. Bu metafor ise "normal düzeyde olan öğrencilerin düşünemediği ve yapamadığı bir çok şeyi çok hızlı ve olağanüstü bir şekilde yapabilmektedir." (59E) açıklanmıştır. "fonksiyon" (22K) metaforunu oluşturan öğretmen ise oluşturduğu metaforu "belirli modellerle farklı bir ürün oluştururlar" şeklinde ifade etmiştir.

\subsection{Tema: Parlak Öğrenci}

Çalışma grubundaki öğretmenlerin oluşturdukları metaforların toplandıkları bu temanın ortak özelliği; "üstün zekâlı öğrenci" kavramının üstün zekâlı olmayan "parlak öğrenci" ya da "çalışkan öğrenci" kavramı ile karıştııılmasıdır. Bu tema altındaki metaforlar Tablo-5'deki gibidir.

Tablo 5. Parlak öğrenci teması altında toplanan metaforlar

\begin{tabular}{lll}
\hline Ansiklopedi (91K) & Kütüphane (92E) & Hiper-aktif öğrenci (4E) \\
Hesap makinesi (87K) & Bilgisayar (74K) & Doğaçlama yapan stand-up'çılar (18E) \\
Kalem (77K) & Bilgisayar (76K) & Hazine (32E) \\
Bilgisayar (50E) & Bilgisayar (82E) & Kaydedici cihaz (38E) \\
\hline
\end{tabular}


Bu temadaki "ansiklopedi" metaforunu oluşturan öğretmen oluşturduğu metaforu ise şöyle açıklarken kullandığı ifadeler "Çeşitli bilgilere sahip olup birçok konu hakkında çok farklı yorumlar bilgiler ortaya çıkarırlar. Kısaca her sorunun cevabını alabiliriz." (91K) Şeklindedir. "Kütüphane" metaforunun açıklaması ise "Çeşitli bilgilere sahip ve çoğu bilgileri akıllarında tutarlar. Herhangi bir kütüphaneye girip nasıl okuldaki sorunların cevabını alıyorsak üstün zekâlı öğrencide her sorunun cevabını verebiliriz." (92E) Yine bu tema altında en çok oluşturulan "bilgisayar" metaforlarını oluşturan öğretmenlerden bir tarafından açıklanması "Bilgisayar gibi zekâya sahiptirler. Bilgileri olduğu her konuda anında cevap verebilme yeteneğine sahiptir o bilgi bolluğuna sahiptirler." (82E) şeklindedir. "Kalem" metaforunu ise "Birçok bilgiyi bildikleri için makale yazar gibi bilgilerini yazarlar." (77K) ifadeleri ile anlamlandırımıştır.

\subsection{Tema: Yüksek Zihinsel Kapasite}

Çalışmadaki bu tema altında toplanan metaforlar üstün zekâlı bir bireyin zihinsel kapasitesi ile ilgilidir. Bu tema altında oluşturulan metaforlar Tablo-6'daki gibidir:

Tablo 6: Yüksek zihinsel kapasite teması altında toplanan metaforlar

\begin{tabular}{lll}
\hline Hesap Makinesi (14E) & Bilgisayar (57E) & Baraj (30E) \\
Değirmen (29E) & Barajda Biriken Su (48E) & Bilgisayar (16K) \\
Deniz (41E) & Bilgisayar (94K) & Hesap Makinesi (62K)
\end{tabular}

Bu tema altındaki "hesap makinesi" metaforlarını "Her türlü zorluğu, karmaşıklığı aşabilecek kapasiteye sahiptir." (14E) ve "Özellikle matematiksel zekâları hesaplamaya çok elverişli olduğundan, istenilen matematiksel hesaplamayı tabir-i caizse hesap makinesi gibi yaparlar." (62K) şeklinde açıklamışlardır. Bilgisayar metaforunu oluşturan öğretmenler ise "beyinleri çok aktif" (16K), "yüksek işlem yetenekleri var" (57E) ve "Bir anda birçok işlemi yapabilir, çok yönlü düşünebilir aynı anda birçok işi yapabilirler." (94K) ifadeleri ile açıklamışlardır.

\subsection{Tema: Değerli}

Bu tema altında toplanan metaforlar üstün zekâlı bireylerin değerli yönleri ile ilgilidir. Bu tema altındaki metaforlar Tablo-7'deki gibidir.

Tablo 7. Değerli teması altında toplanan metaforlar

\begin{tabular}{llc}
\hline Oksijen (2K) & Gizli kalmış maden (15K) & Anlaşılmayan bir kitap (80E) \\
Elmas (6E) & Altın (46E) & Değerli bir taş (8K) \\
Su (5K) & Kapalı kutu (61K) & içinde mücevher barındıran çok sıkı bir kutu (20K)
\end{tabular}

Bu tema altındaki metaforlardan "altın" metaforu "iyi kullanırsa çok iyi bir değer alır" şeklinde açıklanmıştır. "Elmas" metaforu ise "zor bulunur ve de klymetlidir" şeklinde ifade edilmiştir.

\subsection{Tema: Anlaşılmayan Birey}

Bu tema altında toplanan metaforlar üstün zekâlı bireylerin çevreleri tarafından anlaşılamama ve çevreleri ile iletişimleri merkezinde toplanmıştır. Bu tema altında toplanan metaforlar Tablo-8'deki gibidir.

Tablo 8. Anlaşılmayan birey teması altında toplanan bireyler

\begin{tabular}{ll}
\hline Sevilmeyen bir kedi (78E) Oyun halkası (74K) & Gezegenler (27E) \\
Dikkatle keşfedilmesi gereken bir dünya (3E) & Kapalı kutu (61E) \\
İcinde mücevher bulunduran çok sıkı bir kutu (20K) &
\end{tabular}

Bu temadaki "sevilmeyen bir kedi" metaforu "Yaşıtları ve toplum tarafından dışlanmış gibi görünseler de kendi dünyalarında bütün herkesi dışlamıştır. Onların uğraştığı şeyler boş gelir her 
zaman uğraşacak daha önemli şeyler bulurlar" (78E) şeklinde ifade edilmiştir. "Oyun halkası" metaforu ise "Kendi duygularını mantıklarını düşündükleri an başkasının düşüncesinden hoşlanmayabilirler. Kendi yaptıkları daha zeki gelir. O yüzden başkalarını halkanın dışında hissederler. Olaylardan soyutturlar." (74K) ifadeleri ile oluşturulan öğretmen tarafından açıklanmıştır.

\subsection{Tema: Faydalı}

Bu tema altında toplanan metaforlar üstün zekâlı bireylerin çevrelerine faydalı olma şeklinde ifade edilebilir. Bu tema altındaki metaforlar Tablo-9'daki gibidir.

Tablo 9. Faydalı teması altında toplanan metaforlar

\begin{tabular}{lll}
\hline Ampul (23K) & Meyve veren ağaç (56K) & Işık (17E) \\
Güneş (34E) & Güneş (36K) & Eşsiz pırlantalar (21K) \\
Yağmur (35K) & Taze Fidan (42E) & Işık (53E) \\
Oksijen (2K) & Su (5K) &
\end{tabular}

Bu tema altındaki iki defa oluşturulan "güneş" metaforunun açıklamaları "Etraflarına hiç olmadık fikirler sunarak bizleri aydınlatırlar. Bizlere de farklı düşünceleriyle etkilerler" (34E) ve "kendilerini donattıkları gibi etraflarını da aydınlatır hem kendi hem de başkalarının hayatlarını kolaylaştırırlar." (36K) şeklindedir. "Işık" metaforu ise "Bu öğrencilerin doğru eğitimle ülkenin daha bağımsız ve hızlı kalkınmasını sağlayacaktır." (53E) şeklinde ifade etmiştir.

\subsection{Tema: Gelişen}

Bu tema altında toplanan metaforların ortak özelliği "üstün zekâ" kavramının gelişim gösteren bir kavram olmasıdır. Bu temadaki metaforlar Tablo-10'da gösterildiği gibidir:

Tablo 10. Gelişen teması altında toplanan metaforlar

\begin{tabular}{|c|c|c|}
\hline Teknoloji (94K) & Bilgisayar (89K) & Teknoloji (70K) \\
\hline Akıllı telefon (87K) & Demir (72K) & Uyuyan volkanik dağ (69E) \\
\hline
\end{tabular}

\subsection{Tema: Zararlı Olabilir}

Bu tema altında toplanan metaforların ortak özelliği üstün zekanın "olumsuz" bir yanı olmasıdır. Bu tema altında toplanan metaforlar Tablo-11' de gösterildiği gibidir.

Tablo 11. Zararlı olabilir teması altında toplanan metaforlar

\begin{tabular}{ll}
\hline Hediye kutusu (25K) & Deniz (42K) \\
Bitki (51K) & Oyun hamuru (52K)
\end{tabular}

Oyun hamuru metaforu “oyun hamuruna istenilen şekil verilebildiği gibi üstün zekâlı öğrenciye de istenilen şekil verilebilir zekâyı olumlu ya da olumsuz yönde kullanması konusunda yönlendirilebilir." (52K) ifadeleri ile, Bitki metaforuysa "uygun şartlarda yetiştidirildiğinde bitkiler gibi faydalı olacaktır. Topluma çorak topraklarda kaldığında ise var olan zekâsını topluma zararlı olacak şekilde kullanabilir. Verimli topraklarda güzel faydalı bitkiler, çorak topraklarda ise zararlı bitkiler yetişir." (51K) şeklinde açıklanmıştır.

\subsection{Tema: Enderlik}

Bu temanın ortak özelliği üstün zekâlı bireylerin nadir bulunma yönüdür. Bu tema altında toplanan metaforlar Tablo-12'de gösterildiği gibidir. 
Tablo 12. Enderlik teması altında toplanan metaforlar

\begin{tabular}{ll}
\hline Piyango (71E) & Gezegen (28E) \\
Elmas (7E) & Kartal (85E)
\end{tabular}

Burada "Piyango" metaforu oluşturan öğretmen tarafından "Ömür boyu başlarına gelen bir piyango gibidirler. Piyangolarda çok düşük intimallerle çıkıyor. Bana göre üstün zekâlıık nedir ve kişi için çok üst seviye bir özelliktir. Kullanmayı bildikten sonra çok şey yapabilir." (71E) bir diğer metafor olan "Elmas" metaforuysa "zor bulunur ve de kıymetlidirler." (7E) şeklinde ifade edilmiştir.

\section{YORUM VE TARTIŞMA}

Matematik öğretmenlerinin üstün zekâlılar hakkında oluşturdukları metaforlarının incelendiği bu çalışmada, 94 metafor 10 kategori altında toplanmıştır. Bu kategorilerden "Hassas bir eğitim", "Farklı", "Yüksek zihinsel kapasite", "Değerli" ve "Anlaşılmayan birey" kategorileri Özsoy (2014) ve Çapan (2010) çalışmalarındaki temalar ile büyük benzerlikler göstermektedir. Stenbergen ve Zhang (1995) Beşgen Kuramı'ndan bir bireyin üstün olarak kabul edilebilmesi için yeteneğinin toplum tarafından değerli olması gerektiğini belirtmişlerdir. Stenberge ve Zhang daha da ileri giderek bir bireyin bir alanda çok yetenekli olabileceğini buna karşın eğer toplum bu yeteneğe değer vermiyorsa bu bireyin üstün zekalı olarak değerlendirilemeyeceğini belirtmişlerdir. Toplumların gelişimlerinde son derece önemli ve katkıları normal zeka düzeyine sahip insanlardan kat kat fazla olan üstün zekalı ve yetenekli bireylerin kabiliyetleri sadece kendileri ve aileleri için değil bütün bir toplum için bir hediye olduğunu belirten yazarlar vardır (Davis,2014; Ataman,2014). Bu açıdan katılımcıların üstün zekalı öğrencilerin değerli olduklarının farkında oldukları ve üstün zekanın bir "hediye" olduğunun bilincinde oldukları söylenebilir.

Zeka ve özellikle üstün zekanın yapısı hakkında ilk çalışmaları yapan bilim insanı Sir Franis Galton (1869) dehaları incelendiği çalışmasında zekanın kalıtsal ve sabit olduğunu, çevrenin zekanın üzerinde etkisinin yok denecek kadar az olduğunu öne sürmüştür. "Sabit zeka" olarak bilinen bu anlayışa göre kişinin bilgi seviyesi zamanla değişebilir buna karşın bilgiyi işleme, düşünme hızı vb. zihinsel yetenekler sabittir ve kalıtım ile önceden belirlenmiştir. Yaklaşık 100 yıl sonra zeka üzerinde yapılan araştırmalar sonucunda araştırmacılar zekanın eğitilebildiğini ve IQ'nun değişebileceğini ve "etkileşimli zeka" kavramını ortaya çıkarmıştır. Etkileşimli zeka kavramına göre; zeka gelişimi 18 yaşında durmuyor ve çevresel etmenlere bağlı olarak ileriye veya geriye doğru gidebilir (Clark, 2014 s:5). Bu çalışmaya katılan öğretmenlerin bir kısmı öğrencilerin zihinsel yeteneklerinin sabit olmadığını çevresel etmenlere bağımlı olarak gelişebileceğini veya tam tersi bir durumun oluşabileceğinin farkında oldukları söylenebilir.

"Farklı" temasının ortak özelliği olan "farklı" veya "beklenmedik" olma durumu bazı araştırmacılara göre yaratıcı düşünmenin temel bir bileşenidir. Fisher ve Willams (2004) yaratıcı düşünmenin birinci prensibi olarak "üretmek" veya "ortaya koymak" bunun yanında ise ikinci prensibi olarak ise "farklıık" ve "çeşitlilik" olduğunu belirtmiştir. Boden (1996) ise bilim insanlarının genellikle yaratıcılığı "eski fikirlerin yeni kombinasyonu" olarak tanımladıklarını belirtmiştir. Üstün zekâlılar eğitiminde çok önemli bir isim olan Renzulli (1978) ise meşhur Üçlü halka modelin 'de yaratıcılığı üstünlüğün 3 temel bileşeninden biri olarak tanımlamıştır ve genellikle "üstün zekâlı" ve "yaratıcı" kelimelerinin eş anlamlı olarak kullanıldığını belirtmiştir.

Metaforlar ise kişinin bir olgu hakkındaki zihinsel imgeleri veya o olgu hakkındaki deneyimleri olduğu için bu tema altında toplanan metaforları oluşturan öğretmenlerin üstün zekâ ile yaratıcı düşünme arasındaki ilişkiyi deneyimledikleri ve zihinlerinde üstün zekâlı bir birey dendiğinde yüksek yaratıcılığı yüksek olan bir birey imgesi canlandığı söylenebilir.

Literatürde sorulara hızlı cevap verebilmenin ve soruların cevaplarını bilmenin genellikle "parlak" veya "çalışkan" öğrencilerle ilişkilendirildiğini buna karşılık olarak ise üstün zekâlı olmanın daha çok öngörülemeyen sorular sorma ile ilişkilendirilebileceğini belirten yazarlar mevcuttur (Kingore, 2003; 
Szabos,1989). Bu durum ise oluşturduğu metaforlar "Parlak öğrenci" teması altında toplanan öğretmenlerin üstün zekâlı öğrenciler hakkında yanlış bir inanca ve anlayışa sahip oldukları şeklinde yorumlanabilir.

Stenberg ve Zhang (1995)'ın Beşgen Kuramı'nda üstünlüğün beş boyutu olduğunu ve bu boyutları olağanüstülük, enderlik, değerlilik, üretkenlik ve kanıt olarak sıralamıştır. Bu çalışmadaki 3 tema ise beşgen kuramının üç boyutu ile birebir eşleşmektedir ve bu eşleşen temalar: değerli, enderlik ve yüksek zihinsel kapasite'dir. Bununla birlikte literatürdeki diğer üstün zekâ kuramları incelendiğinde yüksek zihinsel gücün veya işlem kapasitesinin üstünlüğün en temel şartı olduğu görülebilir (Renzulli, 1978; Stenberg ve Zhang,1995; Gagne, 2005)

Literatürde üstün zekâlıların Clark (2013) üstün zekâlı çocukların kendilerini oldukları gibi kabul etmeyi, diğerlerine benzeşen yönlerini ve farklılaşan yönlerini takdir etmeyi öğrenmeleri için çevrelerinden gelecek desteğe ihtiyaçları olduğunu belirtmiştir. Bu destek göremeyen ve sorunlarla başa çıkmakta zorlanan üstün zekâlıların genellikle dünyaya adapte olabilmek için üç yöntem kullandıklarını ve bu yöntemlerin arkasında yatan sebebin tamamen olumlu yönde dikkat çekme ve kabul görme istekleri olduğunu belirtmiştir. Birinci yöntem geri çekilerek kendilerini dünyadan soyutlama, ikinci yöntem sınıfın veya grubun palyaçosu olabilme eğilimi ve son olarak ise çevresindekilere uyum sağlayabilmek için cevapları bilmiyormuş gibi yaparak zekâsını gizlemek şeklindedir. Bu açıdan bakıldığında bu gruptaki öğretmenlerden bazılarının üstün zekâlıların bu yöndeki ihtiyaçlarının farkında olduğu söylenebilir.

Son söz olarak bu çalışma matematik öğretmenlerinin üstün zekalılar hakkındaki meslek hayatlarında edindikleri tecrübelerin ve onlar hakkındaki görüşlerinin incelenmesi amaçlanmıştır. Bu amaç doğrultusunda katılımcılardan metaforlar oluşturmaları istenmiştir. Her ne kadar metaforlar deneyimleri iletmenin güçlü ve etkili yolları olsalarda bizlere kısıtlı bilgiler vermektedirler. Ek olarak, bu çalışmanın Türkiye'nin güneydoğu bölgesinde yapılmış olması ve çalışmaya katılan öğretmenlerin \%85'ten fazlasının meslek hayatlarının ilk 10 yılı içerisinde olması bu çalışmanın sınırlııkları arasındadır. Bu konunun daha iyi anlaşılabilmesi için Türkiye'nin diğer bölgelerinde de görev yapmış ve daha tecrübeli öğretmenlerin katıldığı yeni nitel ve nicel çalışmalara ihtiyaç vardır.

\section{Kaynakça}

Abawi, L. (2013). Metaphor: Powerful imagery bringing learning and theaching to life. Improving Schools, 16(2), 130-147.

Ada, S. (2013). Öğrencilerin matematik dersine ve matematik öğretmenine yönelik algılarının metaforlar yardımı ile belirlenmesi. (Yayımlanmamış yüksek lisans tezi). Gazi Üniversitesi Eğitim Bilimleri Enstitüsü, Ankara.

Ateş, H. K. (2018). Gifted children metaphor from the perspective of teachers and parents. Journal for the Education Of Gifted Young Scientists, 6(2), 30-42.

Boden, M. A. (1996). Dimensions of creativity. https://books.google.com.tr/books?hl=tr\&lr= \&id=xo4C 6 bjid0C\&oi=fnd\&pg=PP9\&dq=2.\%09Boden,$+M .+A .+(1996) .+$ Dimensions + of + creativit y\&ots=AKaTa643PU\&sig=H-xCppJpkmHOJyLUb0zfoYgGZw\&redir esc=y\#v=onepage\&q=2.\%09Boden\%2C\%20M.\%20A.\%20(1996).\%20 Dimensions\%20of\%20creativity\& $f=$ false adresinden 06.05.2017 tarihinde erişim sağlanmıştır.

Büköztürk, Ş., Akgün, Ö.E., Karadeniz, Ş., Demirel, F. ve Kılıç, E. (2016). Bilimsel araştırma yöntemleri. Pegem Akademi Yayıncılık: Ankara

Clark, B. (2015). Üstün zekâlı olarak büyümek: Evde ve okulda çocukların potansiyellerini geliştirmek (Çev. Ed. F. Kaya, Ü. Ogurlu). Nobel Akademik Yayıncılık (Orijinal çalışmanın yayın tarihi 2013).

Cerit, Y. (2008). Öğretmen kavramı ile metaforlara ilişkin öğrenci, öğretmen ve yöneticilerin görüşleri. Türk Eğitim Bilimleri Dergisi, 6(4), 693-712. 
Çapan Bahtiyar, E. (2010). Öğretmen adaylarının üstün yetenekli öğrencilere ilişkin metaforik algıları. Uluslararası Sosyal Araştırmalar Dergisi 3(12).

Çırak, S (2014). Ortaokul öğretmenlerinin 'öğrenci' kavramına ilişkin metaforik algıları. Mustafa Kemal Üniversitesi Sosyal Bilimler Enstitüsü Dergisi, 11(27), 221-336.

Farrel, T. S. C. (2006). 'The teacher is an octupos': Uncovering preservice english language teachers' prior beliefs through metaphor analysis. RELC, 37(2), 236-248.

Fisher, R. ve Williams, M. (2004). Unlocking creativity: Teaching across the curriculum. https://books.google.com.tr/books?hl=tr\&lr=\&id=W6WOTKVVjCwC\&oi=fnd\&pg=PP2\&dq=4.\%0 9Fisher, $+R_{.},+\% 26+$ Williams, + M.+(2004).+Unlocking+creativity:+Teaching+across+the+curriculu m.+Routledge\&ots=aqxp3otkBU\&sig=5YS kGzaYgL5hAhS3CWmsGgBRXk\&redir esc=y\#v=one page\&q\&f=false adresinden 06.05.2017 tarihinde erişim sağlanmıştır.

Gagne, F. (2005). From gifts to talents: The Dmgt as a devolopmental Model. Stenberg ve Davidson (Ed). Conception of giftedness (pp: 98-120). New York: Cambridge.

Gardner, H. (1987). The theory of multiple intellenges. Annals of Dyslexia, 37, 19-35.

Kendal Julia E. ve Kendal Kenneth E. (1993). Metaphors and methodologies: Living beyond system machine. MIS Quarterly, 17(2), 149-171.

Kingore, B. (2003). High achiever, gifted learner, creative thinker. www.runkle.org/wpcontent/uploads/High-Achiever-Gifted-Learner-Creative-Thinker.doc adresinden 06.05.2017 tarihinde erişim sağlanmıştır.

Kunt, K. ve Tortop Hasan, S. (2013). Türkiye'de üstün yetenekli öğrencilerin bilim sanat merkezlerini ilişkin metaforik algıları. Üstün Yetenekli Eğitimi Araştırma Dergisi 1(2), 117-127.

Merriam, S.B. (2013). Nitel araştırma: Desen ve uygulama için bir rehber. (Çev. D.A. Turan). Nobel Akademik Yayınları, (Orijinal çalışmanın yayınlanma tarihi, 2009).

Nikitina, L. ve Furuoka, F. (2008). "A language teacher is like...": Examining malaysian students' perceptions of language teachers through metaphor analysis. Electronic Journal of Foreign Language Teaching, 5(2), 192-205

Olthouse, J (2014). How do preservice teacher conceptiualize giftedness? A metafor analysis. Roepeer Review, 36(2), 122-132, DOI: 10.1080/02783193.2014.884200.

Oxford, R., Tomlinson, S., Barcelos, A., Harrington, C., Lavine, R. Z. ve Saleh, A. (1998). Clashing metaphors about classroom teachers: Toward a systematic typology for the language teaching field. System, 26(1), 3-50.

Özsoy, Y. (2014). Bilim ve sanat merkezi öğrenci, öğretmen ve velilerinin üstün yetenekli öğrenci kavramına iliş̧in metaforları. Üstün Yetenekliler Eğitimi Araştırmaları Dergisi, 2(1), 74-87.

Patton, M. Q. (2014). Nitel araştırma ve değerlendirme yöntemleri. (Çev Ed. M. Bütün ve S.B. Demir). Pegem Akademi Yayınları.

Renzulli, J. (1978). What makes giftedness? Reexamining a definition. Phi Delta Kappa, 6(30) 180-184.

Saban, A. (2008). Okula ilişkin metaforlar. Kuram ve Uygulamada Eğitim Yönetimi, 55, 459-496.

Saban, A. (2009). Öğretmen adaylarının öğrenci kavramına karşı sahip oldukları zihinsel imgeler. Türk Eğitim Bilimleri Dergisi, 7(2), 281-326.

Schultze, U. ve Orlikowski Wanda J. (2001). Metaphors of virtuality: Shaping an emergent reality. Information and Organization, 11, 45-77.

Sternberg, R. J. ve Zhang, L. (1995). What we do mean by giftedness? A pentagonal implicit theory. Gifted Child Quarterly, 39(2), 88-94.

Szabos, J. (1989). Bright child, gifted learner. sww.frenship.us/cms/lib3/TX01917862 /Centricity/Domain/50/BRIGHT_CHILD_GIFTED_LEARNER.doc adresinden 06.05.2017 tarihinde erişim sağlanmıştır.

Yıldırım, A. ve Şimsek, H. (2013). Sosyal bilimlerde nitel araştırma yöntemleri. Ankara: Şeçkin Yayınları. 


\section{Extended Summary}

\section{Purpose}

Metaphors act as a lens, a screen, or a filter through which a subject is viewed and become a mental model for thinking about a phenomenon in light of another (Saban, 2009). Also, metaphors are powerful mental constructs that shape the world and reality that human beings are currently evolving. Metaphors have the power to influence how an individual think and perceive the world around them. In this respect, it is possible to know someone's belief and thought through his or her use of metaphor for any phenomena. In other words, people use metaphors to simplify and explain their experiences (Farrel, 2006). Lakoff and Johnston quoted the role of metaphors on our thinking and behaving: "We define our reality in terms of metaphors and then proceed to act on the basis of the metaphors" (as cited in, Abawi, 2013). In addition, there is a scientific piece of evidence that students see mathematics as "hard and boring subject" and they see their math teachers as an "intelligent person" (Ada, 2015). So, the main purpose of this study is to investigate how these intelligent people, math teachers, see gifted students or what is the mental image of math teachers about gifted students.

\section{Methods}

Altogether a total of 115 math teachers participated in this study. $58.5 \%$ of the participants were women and 41.5 of them were men. Also, 53.2 of the working group were teaching at the middle school and the rest of them were teaching at the high schools. Majority of participants were teaching in Ceylanpinar town center (district of Sanliurfa), and the rest of them were teaching in Kilis city center in 2016. To collect the data participants were asked the complete the following sentence: "Gifted students are like Because ." By completing this sentence participant teachers were expected to produce a metaphor about gifted students and their experience with gifted students. Same metaphors can have different meanings depending on how the user uses it. To avoid these problems participants had to explain the meaning of their metaphors. In doing so, we had a change to understand participants experience about gifted students. Total 115 metaphors have produced by participants. After the data collection, all these metaphors have been examined according to the definition of metaphors. Then, 21 metaphors have been found invalid for different reasons and been excluded to be analyzed by the researchers. Then, total 94 metaphors were accepted as valid metaphors and analyzed by the researchers. After the elimination process then data analysis steps took place. Since the aim of this study is to investigate how math teachers see gifted students and so; their experiences were the source of our study. The experience is the source of the phenomenological study and how these experiences become consciousness (Merriam, 2013). So, content analysis was one of the best ways to analyze and interpret the collected data. In this step, our target was the sorting and categorizing the valid metaphors. The first author has sorted out and categorized the collected data (metaphors) then the second author checked and these categories. By doing this the internal consistency of the study has been done.

\section{Results}

Among all valid 94 metaphors the most common metaphors were "computer" $(f=10)$ and "calculator" ( $f=3$ ) was the second most common one. Then, all valid metaphors are gathered around 10 conceptual themes and these themes are as follows: 15 teachers were aware of gifted students need "a sensitive education" rather than ordinary education. 14 teachers said gifted students "different or unexpected" somehow from their non-gifted peers, 12 teachers' metaphors revealed that these teachers have confusion gifted students with non-gifted but high achiever "bright student". 9 teachers saw gifted students as a person who has "highly intellectual capacity", 9 teachers imagine gifted students as something "precious", 6 teachers were well aware of that gifted ones are kind of "enigma" people that no one understand them, 11 metaphors reveal that 
gifted students are "beneficial" to their society as well as entire humanity. 6 math teachers saw giftedness as a "developing process" instead of something constant, 4 teachers said sometimes being gifted "can be a curse" to himself or herself even their families, and finally 4 participants imagine gifted people were "rare" among population.

\section{Conclusion and Discussion}

The results of this study have revealed all these themes and categories are an important topic that has been debated for a long time in the gifted education. Then an important result of this study is that the majority of math teachers are aware of gifted students and their educational needs. On the contrary, a minority of the working group have confused gifted students with non-gifted, high achievers, and bright students. However, in order to get a better and deeper understanding of this phenomenon more qualitative and quantitative studies are needed. 